\begin{tabular}{|c|c|}
\hline Title & $\begin{array}{l}\text { Synthesis of Enantiomerical ly Enriched Chiral Tetrahydroquinolines via Sequential Dearomatization/Enantioselective } \\
\text { Borylation Reactions }\end{array}$ \\
\hline Author(s) & Kubota, Koji; W atanabe, Y uta; Ito, Haj ime \\
\hline Citation & $\begin{array}{l}\text { A dvanced synthesis \& catalysis, 358(15), 2379-2384 } \\
\text { https://doi .org/10.1002/adsc.201600372 }\end{array}$ \\
\hline Issue Date & $2016-07-29$ \\
\hline Doc URL & http:/hdl.handle.net/2115/66982 \\
\hline Rights & $\begin{array}{l}\text { A dvanced synthesis \& catalysis } 358(15) \text { July } 28,2016 \text { pp.2379-2384, which has been published in final form at } \\
\text { http://Onlinelibrary.wiley .com/doi } / 10.1002 \text { adsc.201600372/abstract. } \\
\text { This article may be used for non-commercial purposes in accordance with Wiley Terms and Conditions for } \\
\text { Self-A rchiving (http://olabout.wiley .com WW ileyCDA Section/1d-828039.html). }\end{array}$ \\
\hline Type & article (author version) \\
\hline File Information & Ito-A SC 358(15).pdf \\
\hline
\end{tabular}

Instructions for use 


\title{
Synthesis of Enantiomerically Enriched Chiral Tetrahydroquinolines via Sequential Dearomatization/Enantioselective Borylation Reactions
}

\author{
Koji Kubota, ${ }^{\text {a }}$ Yuta Watanabe, ${ }^{\mathrm{a}}$ and Hajime Ito ${ }^{\mathrm{a}}$ * \\ ${ }^{a}$ Division of Chemical Process Engineering, Faculty of Engineering, Hokkaido University, Sapporo 060-8628, Japan \\ Fax: +81-11-706-6561; E-mail: hajito@eng.hokudai.ac.jp
}

Received: ((will be filled in by the editorial staff))

Supporting information for this article is available on the WWW under http://dx.doi.org/10.1002/adsc.201\#\#\#\#\#.((Please delete if not appropriate))

\begin{abstract}
A novel approach has been developed for the synthesis of chiral 3-boryl-tetrahydroquinolines via the copper(I)-catalyzed regio- and enantioselective protoborylation of 1,2-dihydroquinolines, which were prepared by the partial reduction of the corresponding quinoline derivatives. This dearomatization/enantioselective borylation sequence has been used to provide facile access to a wide variety of functionalized tetrahydroquinolines under mild conditions from readily available quinoline starting materials in combination with the stereospecific transformation of a stereogenic $\mathrm{C}-\mathrm{B}$ bond. A theoretical study of the mechanism for the enantioselectivity of the reaction has also been described.
\end{abstract}

Keywords: Asymmetric catalysis; Boron; Copper; Synthetic methods

Many pharmaceutical agents and bioactive natural products contain an optically active substituted tetrahydroquinoline scaffold. ${ }^{[1]}$ In particular, chiral 3substituted tetrahydroquinolines can be found in a wide range of drugs exhibiting a broad spectrum of biological activities (Scheme 1). ${ }^{[2]}$ Based on their interesting properties, there has been considerable interest in the development of novel synthetic methods for the preparation of substituted tetrahydroquinolines from researchers working in organic and medicinal chemistry. ${ }^{[3]}$

Optically active organoboron compounds are recognized as useful chiral building blocks in synthetic chemistry because they can be readily applied to the stereospecific functionalization of stereogenic C-B bonds. ${ }^{[4]}$ Considering their great synthetic utility, chiral $N$-heterocyclic organoboronates represent promising intermediates for the preparation of various bioactive molecules and pharmaceutical drugs. ${ }^{[5-7]}$ Despite significant progress toward the development of synthetic approaches for the preparation of chiral boronates, reports pertaining to the catalytic enantioselective construction of these compounds remain scarce. ${ }^{[1,5-7]}$

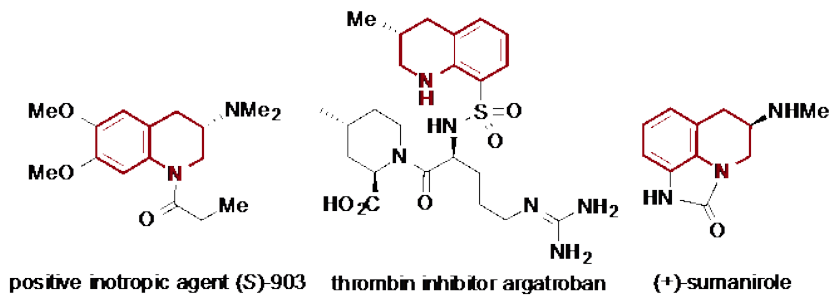

positive inotropic agent (S)-903 thrombin inhbitor argatroban OH

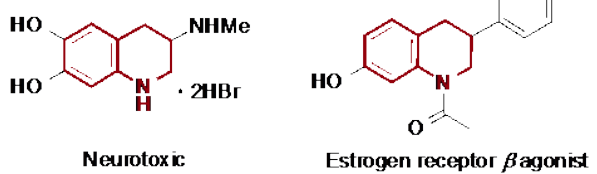

Figure 1. Representative bioactive tetrahydroquinolines.

We recently reported a novel approach to chiral 3boryl-tetrahydropyridines via the copper(I)-catalyzed regio-, diastereo- and enantioselective borylation of 1,2-dihydropyridines, which were prepared by the partial reduction of the corresponding pyridine derivatives (Scheme 1a). ${ }^{[7,8]}$ This dearomatization/enantioselective borylation sequence provided direct access to chiral piperidines from readily available pyridines in combination with the stereospecific transformation of a stereogenic C-B bond. ${ }^{[9]}$ More recently, we turned our attention to the synthesis of chiral boryl-tetrahydroquinolines from quinolines using this sequential dearomative reduction/borylation strategy (Scheme 1b). Pleasingly, we found that the enantioselective protoborylation of 1,2-dihydroquinolines, which were readily prepared by the partial reduction of the corresponding quinolines, in the presence of a copper(I)/(R,R)-QuinoxP* complex catalyst proceeded smoothly to afford the chiral boronates in high yields with excellent regio- and enantioselectivities. ${ }^{[10-13]}$ Furthermore, the chiral 
boronate products could be further functionalized in a stereospecific manner via the oxidation or amination of their $\mathrm{C}-\mathrm{B}$ bond.

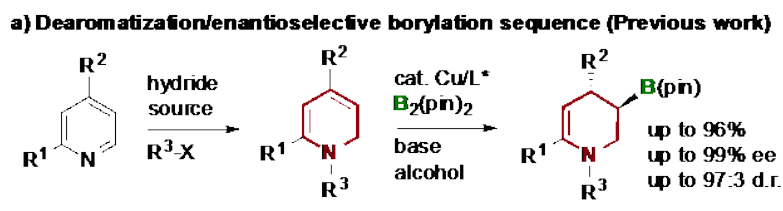

b) Synthesis of chiral boryLtetrahydroquinolines (This work)

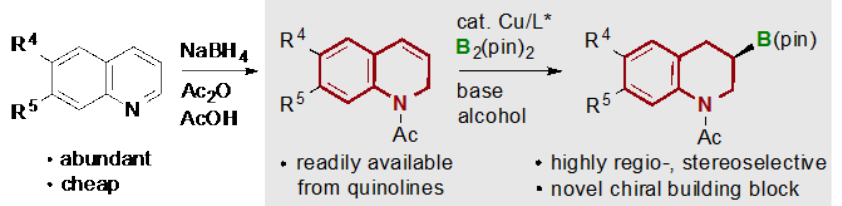

Scheme 1. Dearomatization/enantioselective borylation stepwise strategy for the synthesis of chiral $N$-heterocyclic organoboron compounds.

The results of an extensive series of optimization experiments revealed that the reaction of $N$-acetyl 1,2-dihydroquinoline $\mathbf{2 a}$, which was prepared by the reduction of quinolone (1a) with $\mathrm{NaBH}_{4}{ }^{[14]}$, with bis(pinacolato)diboron (3) (1.2 equiv.) in the presence of $\mathrm{CuCl} /(R, R)$-QuinoxP* (5 mol \%), $\mathrm{K}(\mathrm{O}-\mathrm{t}-$ $\mathrm{Bu})(20 \mathrm{~mol} \%)$ and $\mathrm{MeOH}(2.0$ equiv. $)$ in THF at $-10 \quad{ }^{\circ} \mathrm{C}$ afforded the desired chiral 3-boryltetrahydroquinoline $(R)-\mathbf{4 a}$ in high yield $(90 \%)$ with excellent enantioselectivity (99\% ee) (Table 1, entry $1)$. The use of $(R, R)$-BenzP* or $(R, R)$-Me-Duphos also provided high levels of enantioselectivity (Table 1, entries 2 and 3, 97 and 95\% ee, respectively). Lower chemical yields and enantioselectivities were observed when a triarylphosphine-type ligand, such as $(R)$-BINAP or $(R)$-SEGPHOS was used in the reaction (Table 1, entries 4 and 5). Several other chiral ligands, including $(R, R)$-BDPP and $(R, S)$ Josiphos, were also screened in the reaction. Although these ligands both provided access to the desired borylation product, they afforded poor enantioselectivities (Table 1, entries 6 and $7 ;-14$ and $-29 \%$ ee, respectively). The nature of the proton source was also found to be important to the success of this transformation (Table 1, entries 8 and 9). For example, the use of sterically hindered $t-\mathrm{BuOH}$ instead of $\mathrm{MeOH}$ resulted in a lower yield of the desired product (Table 1, entry 8; 39\%, 95\% ee). Furthermore, the use of $\mathrm{PhOH}$ as a proton source provided a low yield, despite affording a high enantioselectivity (Table 1, entry 9; 48\%, 98\% ee). These results therefore suggest that the proton source is not involved the enantiodetermining step of this reaction. Notably, this enantioselective borylation reaction also proceeded with a $1 \mathrm{~mol} \%$ loading of the copper(I) catalyst and showed good enantioselectivity (87\% ee), although a longer reaction time was required (Table 1, entry 10). Increasing the temperature of the reaction led to a slight decrease in the enantioselectivity (Table 1, entry 11; 85\%, 95\% ee). The reaction proceeded smoothly on a gram scale to give the desired product (1.53 g) with excellent enantioselectivity (Table 1, entry 12, 97\% ee).

Table 1. Optimization of the reaction conditions. ${ }^{[\mathrm{a}]}$

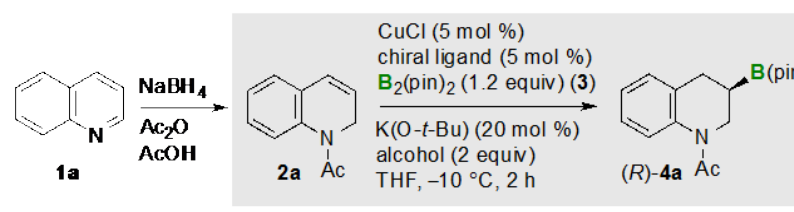

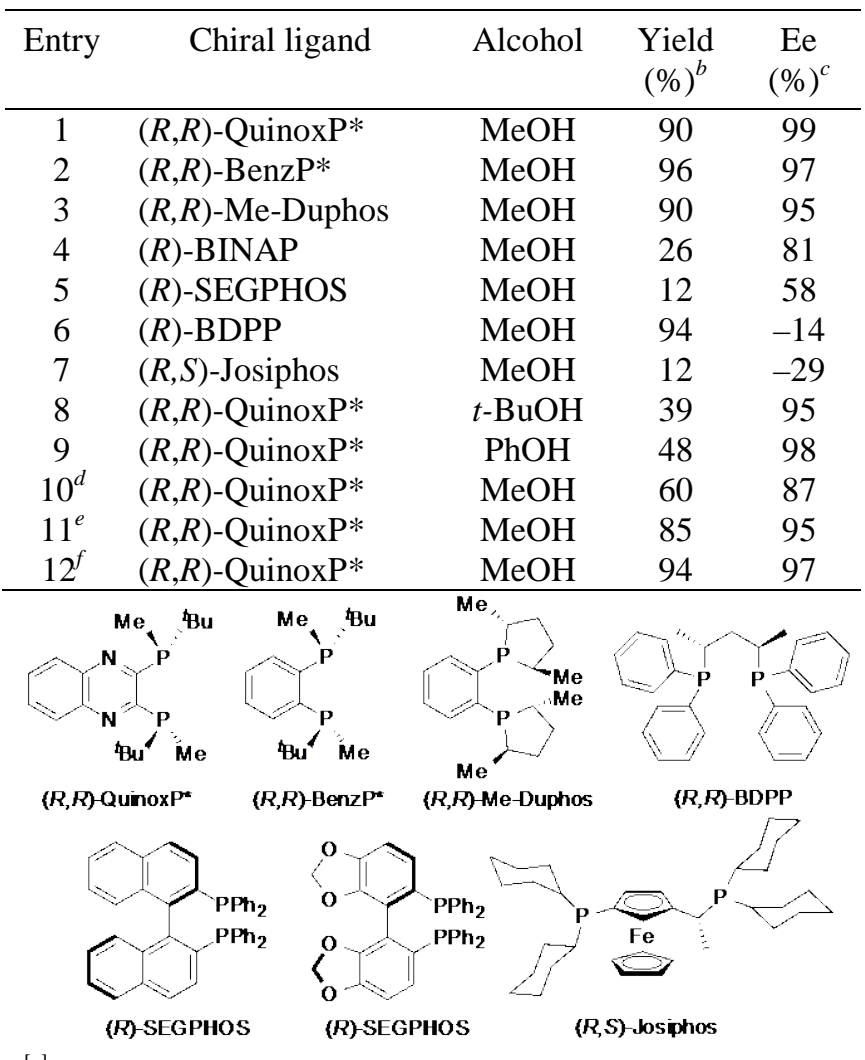

[a] Conditions: $\mathrm{CuCl}(0.025 \mathrm{mmol})$, ligand (0.025 mmol), 2a (0.5 mmol), bis(pinacolato)diboron (3) (0.6 mmol), $\mathrm{K}(\mathrm{O}-\mathrm{t}-\mathrm{Bu})(0.1 \mathrm{mmol})$ and alcohol $(1.0 \mathrm{mmol})$ in THF (1.0 $\mathrm{mL})$.

${ }^{[b]}$ Determined by ${ }^{1} \mathrm{H}$ NMR analysis of the crude reaction mixture with an internal standard.

${ }^{[c]}$ Determined by HPLC analysis.

[d] $1 \mathrm{~mol} \% \mathrm{CuCl}$ and ligand were used in this reaction with a reaction time of $24 \mathrm{~h}$.

${ }^{[\mathrm{e}]}$ The reaction was carried out at $30^{\circ} \mathrm{C}$.

${ }^{[\mathrm{f}]}$ The reaction was carried out on a $5.8 \mathrm{mmol}$ scale.

With the optimized conditions in hand, we provided to evaluate the substrate scope of the reaction using a series of substituted quinolones (Table 2). The borylation products in Table 2 were isolated as the corresponding silyl ethers following the sequential oxidation/silylation of their $\mathrm{C}-\mathrm{B}$ bonds (Please see Scheme 2 and the Supporting Information for further details). ${ }^{[15]}$ 1,2-Dihydroquinolines bearing a Me-, $t$-Bu-, MeO- or TIPS group at their 6-position (2b-e) reacted smoothly in the presence of the copper(I)/(R,R)-QuinoxP* catalyst system to give the desired products $[(R)-\mathbf{4 b}-(R)-\mathbf{4 d}]$ with high 
enantioselectivities (93-98\% ee) (Table 2). In contrast, substrates bearing an electron-withdrawing group such as a halogen or nitro group (2f-2h) provided only moderate enantioselectivities (68-73\% ee) (Table 2). Fortunately, the borylations of $2 \mathbf{f}$ and $2 \mathrm{~g}$ with $(R, R)$-BenzP* instead of $(R, R)$-QuinoxP* showed high enantioselectivities (97\% ee and $96 \%$ ee, respectively). The 7-methyl substituted 1,2dihydroquinoline $2 \mathbf{i}$ was also borylated under the optimized conditions to afford the corresponding 3boryl-tetrahydroquinoline $[(R)-4 \mathbf{i}]$ with excellent enantioselectivity (93\% ee) (Table 2$)$. The borylation of the 7-bromo substituted 1,2-dihydroquinoline $\mathbf{2 j}$ also proceeded well with high enantioselectivity (87\% ee) (Table 2). The copper(I)/(R,R)-QuinoxP* complex also performed as an effective catalyst for the enantioselective protoborylation of the carbamateprotected substrate $\mathbf{2 k}$, which was prepared by a $\mathrm{NaBH}_{4}$ reduction ${ }^{[16]}$, to give the corresponding borylation product $[(R)-4 \mathbf{k}]$ in high yield $(84 \%)$ and enantioselectivity (98\% ee) (Table 2).

Table 2. Substrate scope. ${ }^{[a, b]}$

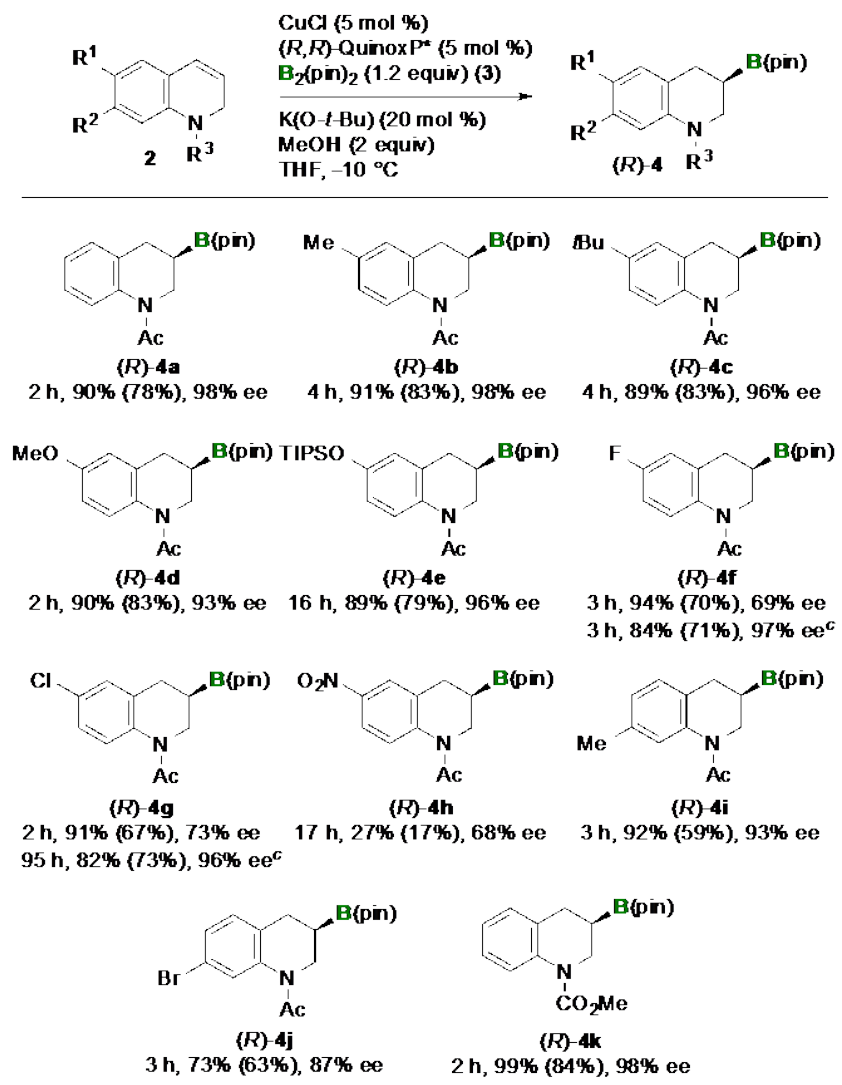

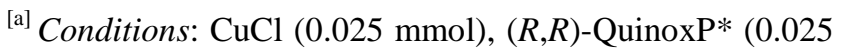
$\mathrm{mmol}), 2$ (0.5 mmol), bis(pinacolato)diboron 3 (0.6 mmol), $\mathrm{K}(\mathrm{O}-t-\mathrm{Bu})(0.1 \mathrm{mmol})$ and $\mathrm{MeOH}(1.0 \mathrm{mmol})$ in THF $(1.0$ $\mathrm{mL})$.

[b] ${ }^{1} \mathrm{H}$ NMR yields of the borylation products. The isolated yields of the corresponding silyl ethers $\mathbf{5}$ after the sequential oxidation/silylation of the borylation products 4 are shown in parenthesis.

${ }^{\text {[c] }}(R, R)$-BenzP* was used instead of $(R, R)$-QuinoxP*.
The borylation products generated in this study could be used as versatile building blocks for the preparation of a wide range of chiral tetrahydroquinolines. For example, the oxidation of the crude mixture resulting from the borylation of $\mathbf{2 a}$ with $\mathrm{NaBO}_{3},{ }^{[17]}$ followed by the sequential silyl protection of the resulting alcohol afforded the chiral tetrahydroquinolinol $(R)-5$ with high enantiomeric excess (Scheme 2). Furthermore, the amination ${ }^{[18]}$ of the crude product $(R)-\mathbf{4 a}$ with $\mathrm{BnN}_{3}$ provided the chiral amine $(R)-\mathbf{6}$ in a stereospecific manner (Scheme 2). Lastly, the oxidation of compound (S)$\mathbf{4 k}$, which was prepared by the borylation of $\mathbf{2} \mathbf{k}$ with $(S, S)$-QuinoxP*, afforded the known chiral alcohol $(S)-7$ in 3 steps from quinoline. Notably, compound (S)-7 is an important intermediate in the synthesis of Sumanirole. ${ }^{[2 b]}$

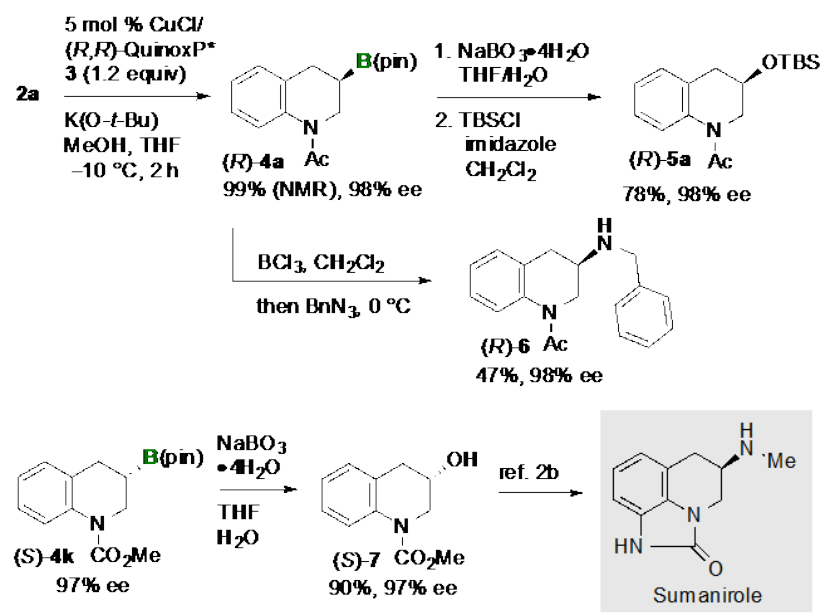

Scheme 2. Synthesis of functionalized chiral tetrahydroquinolines through the derivatizations of the borylation products.

DFT calculations (B3PW91/cc-pVDZ) were conducted to elucidate the mechanism responsible for the enantioselectivity of the current reaction for the borylation of 1,2-dihydroquinolines (Figure 2). The results revealed that the addition of the $(R, R)$ QuinoxP*/borylcopper(I) complex to the Si-face of 1,2-dihydroquinoline 2a would give transition state TS1, ${ }^{[19]}$ which would be free from steric congestion between the $t$-Bu group of the ligand and the 1,2dihydroquinoline scaffold. This reaction pathway would therefore afford the $(R)$-isomer as the major product, which is consistent with the observed absolute configuration of the borylated product. ${ }^{[20]}$ In contrast, the activation barrier for the addition of the complex to the $R e$-face to give transition state TS2 was $+3.35 \mathrm{kcal} / \mathrm{mol}$ higher in energy than that of TS1. This difference in the activation barrier was attributed to steric congestion between the 1,2dihydroquinoline $\mathbf{2 a}$ and the $t$-Bu group on the ligand in TS2, thereby explaining the observed enantioselectivity of this reaction. 

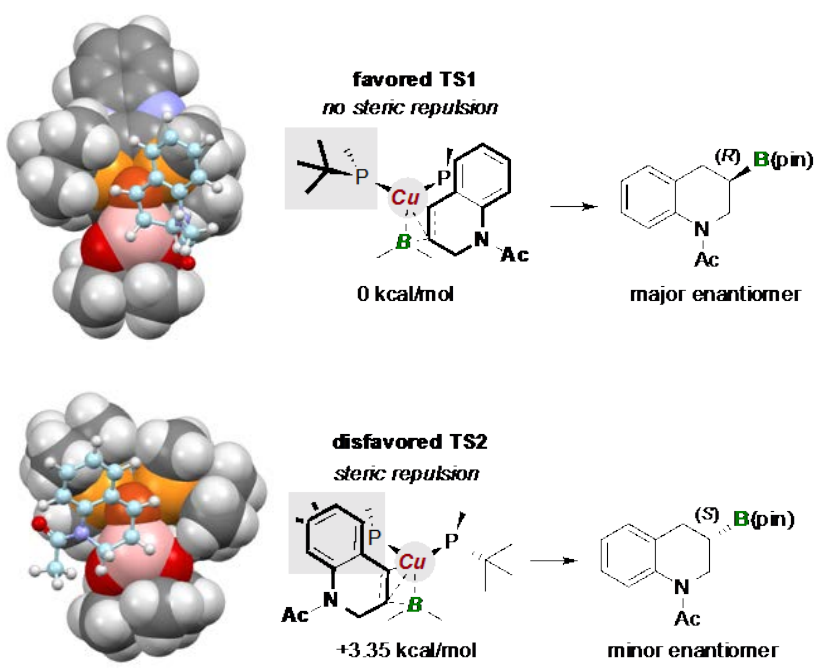

Figure 2. DFT calculations (B3PW91/cc-pVDZ) of the transition states for the $(R, R)$-QuinoxP*/copper(I)catalyzed enantioselective borylation of 1,2dihydroquinoline 2a. Relative $G$ values $(\mathrm{kcal} / \mathrm{mol})$ were obtained at $263 \mathrm{~K}$ and $1.0 \mathrm{~atm}$ in the gas phase.

In summary, we have developed a novel approach to chiral 3-boryl-tetrahydroquinolines via the copper(I)-catalyzed regio- and enantioselective protoborylation of 1,2-dihydroquinolines, which were prepared by the partial reduction of the corresponding quinoline derivatives. This new stepwise strategy represents a simple and direct method for the synthesis of optically active tetrahydroquinolines bearing a C3-stereocenter in combination with a stereospecific boron functionalization process.

\section{Experimental Section}

\section{General Remarks}

Materials were obtained from commercial suppliers and purified by standard procedures unless otherwise noted. Solvents were also purchased from commercial suppliers, degassed via three freeze-pump-thaw cycles and further dried over $4 \AA$ molecular sieves. ${ }^{1} \mathrm{H}$ and ${ }^{13} \mathrm{C}$ NMR spectra were recorded on JEOL JNM-ECX400P spectrometer at 400 and $100 \mathrm{MHz}$, respectively. The peaks corresponding to tetramethylsilane $\left({ }^{1} \mathrm{H}\right)$ and $\mathrm{CDCl}_{3}\left({ }^{31} \mathrm{C}\right)$ were employed as reference standards in the ${ }^{1} \mathrm{H}$ and ${ }^{13} \mathrm{C}$ NMR spectra, respectively. 1,1,2,2-Tetrachloroethane was used as an internal standard to determine the reaction yields by NMR. GLC analyses were conducted on a Shimadzu GC-2014 or GC-2025 system (Shimadzu, Kyoto, Japan) equipped with an ULBON HR-1 glass capillary column (Shinwa Chemical Industries) and an FID detector. HPLC analyses were conducted over a chiral stationary phase on a Hitachi LaChrome Elite HPLC system equipped with an L-2400 UV detector. High-resolution mass spectra were recorded at the Global Facility Center, Hokkaido University.

\section{Representative Procedure for Copper(I)- Catalyzed Enantioselective Borylation of 2a.}

Copper chloride (2.6 mg, $0.026 \quad \mathrm{mmol})$, bis(pinacolato)diboron (153.6 mg, $0.6 \mathrm{mmol}$ ) and $(R, R)$ QuinoxP* (8.4 mg, $0.025 \mathrm{mmol}$ ) were placed in an ovendried reaction vial, which was immediately sealed with a screw cap containing a Teflon-coated rubber septum. The sealed vial was then connected to a vacuum/nitrogen manifold through a needle and vacuum purged with nitrogen three times. THF $(1.0 \mathrm{~mL})$ was added to the vial through the rubber septum, followed by a $1.0 \mathrm{M}$ solution of $\mathrm{K}(\mathrm{O}-\mathrm{t}-\mathrm{Bu})$ in THF $(0.1 \mathrm{~mL}, 0.1 \mathrm{mmol})$, and the resting mixture was cooled to $-10^{\circ} \mathrm{C}$. A solution of $2 \mathbf{a}(92.1 \mathrm{mg}$, $0.53 \mathrm{mmol})$ in $\mathrm{MeOH}(40.5 \mu \mathrm{L}, 1.0 \mathrm{mmol})$ was then added to the cooled mixture at in a dropwise manner $-10{ }^{\circ} \mathrm{C}$. Upon completion of the reaction, as determined by GC analysis and TLC, the reaction mixture was passed through a short silica gel column eluting with $\mathrm{Et}_{2} \mathrm{O}$. The yield of the borylation product $(S)-4 a$ was determined by ${ }^{1} \mathrm{H}$ NMR analysis with an internal standard (83\% NMR yield). The product was isolated following its conversion to the corresponding silyl ether by the oxidation of the boryl group, followed by the TBS protection of the resulting alcohol (78\% isolated yield, 3 steps). The details of these transformations have been described in the Supporting Information.

\section{Supporting Information}

Detailed descriptions of experimental procedures and their spectroscopic data are available in the Supporting Information.

\section{Acknowledgements}

This study was financially supported by the MEXT (Japan) program (Strategic Molecular and Materials Chemistry through Innovative Coupling Reactions) of Hokkaido University, as well as the JSPS (KAKENHI Grant Numbers $15 H 03804$ and 15K13633). K.K. would like to thank the JSPS for their scholarship funding (KAKENHI Grant Number 14J02341).

\section{References}

[1] For selected recent reviews, see: a) K. Kaur, M. Jain, R. P. Reddy, R. Jain, Eur. J. Med. Chem. 2010, 45, 3245-3264; b) V. Sridharan, P. A. Suryavanshi, J. C. Menendez, Chem. Rev. 2011, 111, 7157-7259.

[2] Selected examples of synthesis of bioactive chiral tetrahydroquinolines bearing 3-stereogenic centers, see: a) D. Brundish, A. Bull, V. Donovan, J. D. Fullerton, S. M. German, J. F. Hayler, D. Janus, P. D. Kane, M. McDonnell, G. P. Smith, R. Wakeford, C. V. Walker, G. Howarth, W. Hoyle, M. C. Allen, J. Ambler, K. Butler, M. D. Talbot, J. Med. Chem. 1999, 42, 4584-4603; b) L. Jean-Gerard, F. Mace, A. N. Ngo, M. Pauvert, H. Dentel, M. Evain, S. Collet, A. Guingant, Eur. J. Org. Chem. 2012, 4240-4248; c) P. Ferraboschi, S. Ciceri, P. Grisenti, Tetrahedron Asymmetry 2013, 24, 1142-1147; d) V. Rawat, B. S. Kumar, A. Sudalai, Org. Biomol. 
Chem. 2013, 11, 3608-3611; e) T. Nemoto, M. Hayashi, D. Xu, A. Hamajima, Y. Hamada, Tetrahedron Asymmetry 2014, 25, 1133-1137.

[3] For recent reviews and selected examples of the synthesis of tetrahydroquinolines, see: B. a) Nammalwar, R. A. Bunce, Molecules 2014, 19, 204232; b) M. Fochi, L. Caruana, L. Bernardi, Synthesis 2014, 46, 135-157; c) G. Masson, C. Lalli, M. Benohoud, G. Dagousset, Chem. Soc. Rev. 2013, 42, 902-923; d) X. Jiang, R. Wang, Chem. Rev. 2013, 113, 5515-5546. e) W. Chao, A. T. Jon, J. Am. Chem. Soc. 2008, 130, 8118-8119; f) K. Fukamizu, Y. Miyake, Y. Nishibayashi, J. Am. Chem. Soc. 2008, 130, 10498-10499; g) X. Zhang, X. Han, X. Lu, Org. Lett. 2015, 17, 3910-3913.

[4] Boronic Acids: Preparation and Applications in Organic Synthesis, Medicine and Materials, 2 nd revised ed.; D. G. Hall, Ed.; Wiley-VCH: Weinheim, 2011.

[5] For examples of the preparation and functionalization of chiral 4-boryl-piperidines, see: a) S. Lessard, F. Peng, D. G. Hall, J. Am. Chem. Soc. 2009, 131, 9612-9613; b) J. Ding, D. G. Hall, Angew. Chem. Int. Ed. 2013, 52, 8069-8073; c) J. Ding, T. Rybak, D. G. Hall, Nat. Commun. 2014, 5, 5474-5483.

[6] Enantioselective synthesis of chiral 3-boryl-indolines, see: K. Kubota, K. Hayama, H. Iwamoto, H. Ito, Angew. Chem. Int. Ed. 2015, 54, 8809-8813.

[7] Enantioselective synthesis of chiral 3-boryl-piperidines through the dearomatization/borylation stepwise strategy, see: K. Kubota, Y. Watanabe, K. Hayama, H. Ito, J. Am. Chem. Soc. 2016, 138, 4338-4341.

[8] For pioneering works on the 1,2-borylative dearomatization of pyridines, see: a) K. Oshima, T. Ohmura, M. Suginome, J. Am. Chem. Soc. 2012, 134, 3699-3702. b) A. S. Dudnik, V. L. Weidner, A. Motta, M. Delferro, T. J. Marks, Nat. Chem. 2014, 6, 11001107.

[9] Recent reviews on catalytic enantioselective dearomatization reactions, see: a) C. Zhuo, W. Zhang, S. -L. You, Angew. Chem. Int. Ed. 2012, 51, 12662-12686; b) Q. Ding, X. Zhou, R. Fan, Org. Biomol. Chem. 2014, 12, 4807-4815; c) C. -X, Zhuo, C. Zheng, S. -L. You, Acc. Chem. Res. 2014, 12, 2558-2573.

[10] For selected examples of copper(I)-catalyzed enantioselective protoborylation reactions from our group, see: a) Y. Sasaki, C. Zhong, M. Sawamura, H. Ito, J. Am. Chem. Soc. 2010, 132, 1226-1227; b) K. Kubota, E. Yamamoto, H. Ito, Adv. Synth. Catal. 2013, 355, 3527-3531; c) Kubota, E. Yamamoto, H. Ito, J. Am. Chem. Soc. 2015, 137, 420-424.

[11] For selected examples of copper(I)-catalyzed enantioselective protoborylations, see: a) J. -E. Lee, J. Yun, Angew. Chem. Int. Ed. 2008, 47, 145-147; b) V. Lillo, A. Prieto, A. Bonet, M. M. Diaz-Requejo, J. Ramirez, P. J. Perez, E. Fernandez, Organometallics 2009, 28, 659-662; c) J. M. O'Brien, K.-S. Lee, A. H. Hoveyda, J. Am. Chem. Soc. 2010, 132, 10630-10633; d) A. L. Moure, R. Gómez Arrayás, J. C. Carretero, Chem. Commun. 2011, 47, 6701-6703; e) C. Solé, A. Whiting, H. Gulyás, E. Fernandez, Adv. Synth. Catal.
2011, 353, 376-384; f) J. C. H. Lee, R. McDonald, D. G. Hall, Nature Chem. 2011, 3, 894-899; (g) H. Lee, B. -Y. Lee, J. Yun, Org. Lett. 2015, 17, 764-766.

[12] Copper(I)-catalyzed enantioselective borylation of stylene derivatives, see: a) Y. Lee, A. H. Hoveyda, J. Am. Chem. Soc. 2009, 131, 3160-3161; b) D. Noh, H. Chea, J. Ju, J. Yun, Angew. Chem. Int. Ed. 2009, 48, 6062-6064; c) R. Corberán, N. W. Mszar, A. H. Hoveyda, Angew. Chem. Int. Ed. 2011, 50, 7079-7082; d) X. Feng, H. Jeon, J. Yun, Angew. Chem. Int. Ed. 2013, 52, 3989-3992. In ref. 11a, Hoveyda et al. reported the enantioselective borylation of cyclic stylenes such as 1,2-dihydronaphthalene with a chiral NHC/copper(I) catalysis. However, they did not apply their catalytic system to 1,2-dihydroquinolines.

[13] Recent review on copper(I)-catalyzed borylation reactions, see: K. Semba, T. Fujihara, J. Tereo, Y. Tsuji, Tetrahedron 2015, 15, 2183-2197.

[14] V. K. Tiwari, G. G. Pawar, R. Das, A. Adhikary, M. Kapur, Org. Lett. 2013, 15, 3310-3313.

[15] We tried to isolate the borylation product $(R)-\mathbf{4 a}$ after the reaction, but separation of $(R)-\mathbf{4 a}$ and pinacol was difficult by silica gel column chromatography. The details have been described in the Supporting Information.

[16] F. W. Fowler, J. Org. Chem. 1972, 37, 1321-1323.

[17] G. W. Kabalka, T. M. Shoup, N. M. Goudgaon, J. Org. Chem. 1989, 54, 5930-5933.

[18] E. Hupe, I. Marek, P. Knochel, Org. Lett. 2002, 4, 2861-2864.

[19] The origin of the regioselectivity of the 4,3-addition of the borylcopper(I) complex to 1,2-dihydroquinolines can be explained by the formation of more stable benzylic alkylcopper(I) intermediate compared to the corresponding alkylcopper(I) generated at 3-position in the 3,4-addition.

[20] The absolute configuration of the borylation products was determined by comparison of the optical rotation of (S)-7 and the reported values (ref. 2b). The details have been described in the Supporting Information. 


\section{COMMUNICATION}

Synthesis of Enantiomerically Enriched Chiral

Tetrahydroquinolines via Sequential

Dearomatization/Enantioselective Borylation

Reactions

Adv. Synth. Catal. Year, Volume, Page - Page

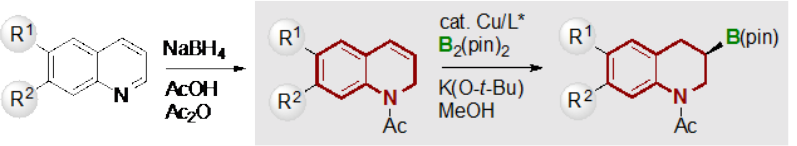

Koji Kubota, Yuta Watanabe, Hajime Ito*

- High yield and enamioselectivity (up to $99 \%$, up to $99 \%$ ee)

- Readidy avadable starting materiats

- Chiral boryltetrahydroquinotines: Useful intemediate 